UNIVERSIDADE DE SÃO PAULO

FACULDADE DE CIÊNCIAS FARMACÊUTICAS DE RIBEIRÃO PRETO

\title{
Plasticidade dos neutrófilos durante a infecção por Mycobacterium tuberculosis está relacionada com a progressão da doenca humana
}

Priscilla Mariane Cardoso Silva 


\title{
UNIVERSIDADE DE SÃO PAULO
}

FACULDADE DE CIÊNCIAS FARMACÊUTICAS DE RIBEIRÃO PRETO

\section{Plasticidade dos neutrófilos durante a infecção por Mycobacterium tuberculosis está relacionada com a progressão da doença humana}

\author{
Dissertação de mestrado apresentada ao \\ programa de Biociências Aplicadas à \\ Farmácia para obtenção do título de Mestre \\ em Ciências \\ Área de Concentração: Biociências \\ Aplicadas à Farmácia \\ Orientado(a): Priscilla Mariane Cardoso \\ Silva
}

Orientador(a): Profa. Dra. Fabiani Gai Frantz 


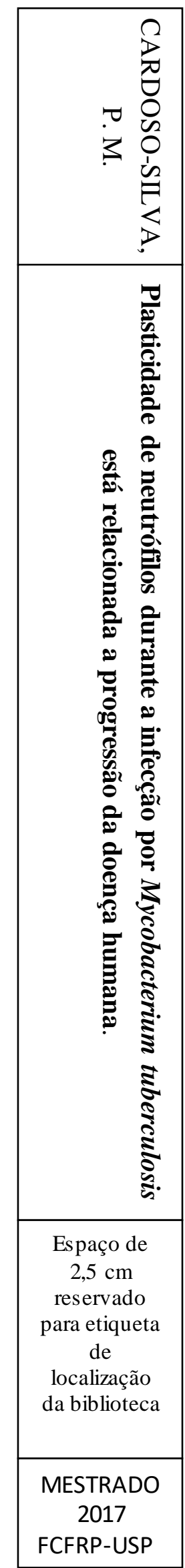


AUTORIZO A REPRODUÇÃO E DIVULGAÇÃO TOTAL OU PARCIAL DESTE TRABALHO, POR QUALQUER MEIO CONVENCIONAL OU ELETRÔNICO, PARA FINS DE ESTUDO E PESQUISA, DESDE QUE CITADA A FONTE.

Cardoso-Silva, Priscilla Mariane

Plasticidade dos neutrófilos durante a infecção por Mycobacterium tuberculosis está relacionada com a progressão da doença humana. Ribeirão Preto, 2017.

99p.: il,; 30cm

Dissertação apresentada a Faculdade de Ciências Farmacêuticas de Ribeirão Preto/USP. Área de concentração: Biociências Aplicadas à Farmácia.

Oroentadora: Frantz, Fabiani Gai.

1. Neutrófilos. 2. Mycobacterium tuberculosis 3.Plasticidade 4. Tuberculose 


\section{FOLHA DE APROVAÇÃO}

Nome do aluno: Priscilla Mariane Cardoso Silva

Título do Trabalho: Plasticidade dos neutrófilos durante a infecção por Mycobacterium tuberculosis está relacionada com a progressão da doença humana

Dissertação de mestrado apresentada ao programa de Biociências Aplicadas à Farmácia para obtenção do título de Mestre em Ciências

Área de Concentração: Biociências Aplicadas à Farmácia

Orientado(a): Priscilla Mariane Cardoso Silva

Orientador(a): Profa. Dra, Fabiani Gai Frantz

Aprovado em:

Banca Examinadora

Prof. Dr.

Instituição: Assinatura:

Prof. Dr.

Instituição: Assinatura:

Prof. Dr. Instituição: Assinatura: 
Agradecimentos 
À minha orientadora Dr(a) Fabiani Gai Frantz pela confiança, pela oportunidade e pela orientação. Muito obrigada por sempre se dispor a dividir comigo seus conhecimentos e me ensinar pacientemente muito sobre a vida e a pesquisa científica. Você é um lindo exemplo de mulher na ciência.

Aos meus pais Jorgina e Lázaro e a minha irmã Victória por me acompanharem desde o início nessa trajetória que escolhi, me apoiando e incentivando, sempre com uma grande atenção e amor. Vocês são inspiração para a minha vida.

Ao meu marido Lucas Calixto por acreditar tanto em mim, por me acompanhar em cada passo. Obrigada por não cansar de me ouvir e estar sempre disposto a me ajudar. Juntos construímos sonhos, e traçamos sempre um caminho.

À Fabiana Albani Zambuzi esse agradecimento é fácil, se resume a: sem você seria impossível. Nunca vou conseguir agradecer o suficiente todo o apoio, a ajuda nos experimentos, as trocas, as discussões, as conversas, a paciência, o carinho e a amizade. Durante esse caminho nos unimos, nos ajudamos e nos fortalecemos diante todos os momentos difíceis. Aprendi muito com você, Fabi, e tenho certeza que o seu futuro será brilhante.

À Luana e Verônica por sempre discutir comigo as duvidas durante esse mestrado e por sempre me ajudar a ultrapassar os obstáculos. A amizade de vocês foi muito importante durante esse processo. Não muito longe, do outro lado da porta, eu também podia sempre contar com a amizade e apoio de vocês, Morgana, Mouzarlem e Karina, muito obrigada.

Aos amigos do LIME (Laboratório de Imunologia e Epigenética), Leonardo, Caroline e Ricardo, obrigada por me acolherem tão bem e pela experiência maravilhosa que foi trabalhar com vocês.

Às minhas amigas Iza, Aninha e Wendy, vocês estão comigo desde o meu primeiro IC, vocês que me ajudaram a entender um laboratório e a amá-lo mesmo quando tudo vai errado. A tranquilidade e a perseverança de vocês me mostraram que os problemas são pequenos e que com dedicação tudo acaba bem.

Aos amigos do LIIP (Laboratório de Inflamação e Imunologia das Parasitoses) Mirela, Gisele, Alyne, Carlos, Luma, Luana, Marcela, Pericles, Priscilla, Ana Paula pela amizade e pela convivência. 
Aos amigos que a USP me deu e àqueles que Ribeirão Preto me apresentou com tanto amor. Obrigada por serem um refúgio nos momentos difíceis.

À professora Dr(a) Lúcia Helena Faccioli por compartilhar da estrutura do seu laboratório.

Ao professor Dr. Valdes Bollela pela parceria no desenvolvimento desse projeto, auxiliando no contato com os pacientes e com a avaliação clínica.

À Equipe do Hospital das Clínicas, do Centro de Saúde Escola e da Unidade de Emergência do Hospital das Clínicas todos sempre contribuíram muito para a realização deste trabalho.

Aos voluntários, aos pacientes, à todos que doaram um pouco do seu sangue para a realização desse trabalho, o meu muito obrigada. Sem o auxilio de vocês nada seria possível.

À Faculdade de Ciências Farmacêuticas de Ribeirão Preto, ao programa de pós-graduação em Biociências Aplicadas a Farmácia.

Ao CNPq e à FAPESP (Processo 2011/12199-0) pelo suporte financeiro durante desenvolvimento do projeto. 


\section{RESUMO}

CARDOSO-SILVA, P. M. Plasticidade de neutrófilos durante a infecção por Mycobacterium tuberculosis está relacionada a progressão da doença humana. 2017. 99 f. Dissertação (Mestrado). Faculdade de Ciências Farmacêuticas de Ribeirão Preto - Universidade de São Paulo, Ribeirão Preto, 2017.

A tuberculose é uma doença infecciosa, causada pela Mycobacterium tuberculosis (Mtb), que afeta um terço da população mundial, sendo que o hospedeiro infectado pode desenvolver tanto a forma ativa quanto latente da infecção. Juntamente com os macrófagos residentes, os neutrófilos parecem ser importantes no controle da infecção por Mtb e formação de granulomas no pulmão. Recentemente, alguns estudos estão quebrando paradigmas sobre os neutrófilos, revelando que em algumas situações como em câncer, essas células podem ser polarizadas para os perfis N1 e N2, associados respectivamente às respostas anti-tumoral e pró-tumoral. Estas descobertas abriram uma perspectiva diferente no estudo de infecções, inclusive na tuberculose. Assim, a hipótese deste trabalho é que a polarização dos neutrófilos nos perfis $\mathrm{N} 1$ e $\mathrm{N} 2$ pode influenciar o controle da infecção por Mtb, e portanto nosso objetivo foi avaliar como estes diferentes perfis estão relacionados com a patogênese da doença humana. Os neutrófilos foram isolados a partir de sangue periférico de 17 voluntários que não apresentavam a infecção ativa por Mtb. Estas células foram polarizadas in vitro com GM-CSF + IFN- $\gamma$ para diferenciação no perfil N1 ou com IL-4 + IL-13 + TGF- $\beta$ para diferenciação no perfil N2. Os neutrófilos polarizados foram caracterizadas por análise morfológica, produção de espécies reativas de oxigênio e expressão gênica. Neutrófilos N1 e N2 foram então infectados in vitro por Mtb e a capacidade fagocítica e microbicida, bem como a liberação de NETs e a produção de citocinas foram analisadas. Os neutrófilos de pacientes com tuberculose ativa foram avaliados quanto a expressão de genes correlacionados aos perfis N1 e N2 e estabelecidas correlações com a gravidade da doença. Quando os neutrófilos foram desafiados com Mtb, o perfil N1 apresenta aumento de IL-8, IL-1- $\beta$, IFN- $\gamma$ e a formação de NETs. Em contraste, o perfil de N2 apresentou menor produção destas citocinas inflamatórias, mas de forma evidente, aumento de IL-4 e TGF- $\beta$. Além disso, na condição N2 não foi possível observar a formação de NETs. Curiosamente, avaliando a atividade microbicida, quando os neutrófilos são polarizados, infectados por Mtb e co-cultivados com PBMC, os mediadores liberados por N1 e N2 potencializam a capacidade dos monócitos em eliminar a micobactéria. Adicionalmente, neutrófilos de 19 pacientes com tuberculose ativa foram avaliados quanto a expressão gênica, e comparadas à expressão dos neutrófilos de indivíduos não infectados. A expressão dos genes TLR4, LCN2 e Dectin1 estava diminuída em neutrófilos de pacientes com tuberculose e expressão do gene CCR7 foi correlacionada negativamente com a progressão da tuberculose, de modo que a maior expressão de CCR7 está relacionada à menor gravidade da doença. A expressão gênica também mostrou diferenças no perfil dos neutrófilos durante as distintas fases de ativação por Mtb. Este resultado reforça a ideia de plasticidade dos neutrófilos de acordo com o microambiente e ajuda a entender melhor como os subtipos de neutrófilos podem ter diferentes ações contra Mtb. Além disso, indica que os N2 estão mais relacionados com a doença na sua fase mais grave, impedindo a resolução ideal da infecção que estaria associada ao perfil N1.

Palavras chave: Neutrófilos, Mycobacterium tuberculosis, plasticidade, tuberculose. 


\begin{abstract}
CARDOSO-SILVA, P. M. Neutrophils plasticity during Mycobacterium tuberculosis infection is related to the human disease progression. 2017. $99 \mathrm{f}$. Dissertation (Master). Faculdade de Ciências Farmacêuticas de Ribeirão Preto - Universidade de São Paulo, Ribeirão Preto, 2017.
\end{abstract}

Tuberculosis is an infectious disease caused by Mycobacterium tuberculosis (Mtb), which affects one-third of the world's population, and the infected host can develop both active and latent forms of the infection. Together with resident macrophages, neutrophils appear to be important in the control of Mtb infection and in the formation of granulomas in the lung. Recently. Some studies are breaking paradigms about neutrophils, revealing that in some situations such as cancer, these cells can be polarized to the $\mathrm{N} 1$ and $\mathrm{N} 2$ profiles, respectively associated with anti-tumor and pro-tumor responses. These findings opened a new perspective on the study of infections, including tuberculosis. Thus the hypothesis of this work is that neutrophil polarization in the $\mathrm{N} 1$ and $\mathrm{N} 2$ profiles may influence the control of Mtb infection, and hence our objective was to evaluate how these different profiles are related to the pathogenesis of the human disease. Neutrophils were isolated from peripheral blood of 17 healthy volunteers and 19 patients with active tuberculosis. Cells from healthy volunteers were polarized with GM-CSF + IFN- $\gamma$ for differentiation in the N1 profile, or with IL-4 + IL-13 + TGF- $\beta$ for differentiation in the N2 profile. Polarized neutrophils were characterized by morphological analysis, production of reactive oxygen species, and gene expression. Neutrophils $\mathrm{N} 1$ and $\mathrm{N} 2$ were then infected in vitro by Mtb and the phagocytic and microbicidal capacity, as well as the release of NETs and the production of cytokines were analyzed. Neutrophils from patients with active tuberculosis were evaluated for expression of genes correlated to $\mathrm{N} 1$ and $\mathrm{N} 2$ profiles and established correlations with disease severity. When neutrophils were challenged with Mtb, the N1 group showed an increase in IL-8, IL-1- $\beta$, IFN- $\gamma$ and formation of NETs. In contrast, the N2 profile reveals a subtle production of these inflammatory cytokines, but clearly, increased IL-4 and TGF- $\beta$. Furthermore, in the (N2) condition it was not possible to observe the formation of NETs. Interestingly, evaluating microbicidal activity, when neutrophils are polarized, infected by Mtb and co-cultured with PBMC, the mediators released by $\mathrm{N} 1$ and $\mathrm{N} 2$ potentiate the ability of monocytes to eliminate mycobacteria. On the other hand, gene expression of neutrophils from patients with tuberculosis showed a decrease in TLR4, LCN2 and Dectin1 genes. CCR7 showed a negative correlation with the progression of tuberculosis, so that the greater expression of CCR7 is related to the lower severity of the disease. Gene expression also showed differences in neutrophil profile during the different stages of activation by Mtb. This result reinforces the idea of plasticity of neutrophils according to the microenvironment and helps to better understand how neutrophil subtypes may have different actions against Mtb. In addition, it also indicates that $\mathrm{N} 2$ is more related to the disease in its most severe phase, preventing the ideal resolution of the infection that would be associated to the $\mathrm{N} 1$ profile.

Key words: Neutrophils, Mycobacterium tuberculosis, plasticity, tuberculosis. 


\section{RESUMEM}

CARDOSO-SILVA, M. P. La plasticidad de los neutrófilos durante la infección con Mycobacterium tuberculosis está relacionado con la progresión de la enfermedad humana. 2017. 99 f. Dissertación (Maestría). Faculdade de Ciências Farmacêuticas de Ribeirão Preto Universidade de São Paulo, Ribeirão Preto de 2017.

La tuberculosis es una enfermedad infecciosa causada por Mycobacterium tuberculosis (Mtb), que afecta a un tercio de la población mundial, y el huésped infectado puede desarrollar tanto la infección activa y latente. Junto con los macrófagos residentes, los neutrófilos parecen ser importantes en el control de la infección por Mtb y formación de granulomas en los pulmones. Estudios recientes están rompiendo paradigmas sobre los neutrófilos. Eses revelaron que en algunas situaciones, como en el cáncer, estas células pueden estar sesgados hacia los patrones de N1 y N2 respectivamente asociados a las respuestas antitumorales y pro-tumorales. Estos resultados han abierto una perspectiva diferente en el estudio de infecciones, incluyendo la tuberculosis. Por lo que la hipótesis es que la polarización de los neutrófilos en N1 y N2 perfiles puede influir en el control de la infección por Mtb, por lo que nuestro objetivo era evaluar cómo estos diferentes perfiles están relacionados con la patogénesis de la enfermedad humana. Los neutrófilos se aislaron de sangre periférica de 17 voluntarios sanos y 19 pacientes con tuberculosis activa. Las células de voluntarios sanos fueron polarizados con GM-CSF + IFN- $\gamma$ de perfil diferenciación N1 o IL-4 + IL-13 + TGF- $\beta$ para diferenciar el perfil de $\mathrm{N} 2$. neutrófilos polarizadas se caracterizaron por el análisis morfológico, la producción de especies reactivas del oxígeno y la expresión génica. Los neutrófilos $\mathrm{N} 1$ y N2 se infectaron entonces con Mtb in vitro y fagocítica y la capacidad microbicida, así como la liberación de NET y la producción de citoquinas se analizaron. Se evaluaron Los neutrófilos de pacientes con TB activa para la expresión de genes relacionados con los perfiles de N1 y N2 y correlaciones establecidas con gravedad de la enfermedad. Cuando los neutrófilos se estimularon con Mtb, grupo N1 tiene una mayor IL-8, IL-1- $\beta$, IFN- $\gamma$ y la formación de los TNE. Por el contrario, el perfil $\mathrm{N} 2$ revela sutil producción de estas citocinas inflamatorias, pero evidentemente, el aumento de IL-4 y TGF- $\beta$. Además, la condición (N2) no se observó la formación de los TNE. Curiosamente, la evaluación de la actividad microbicida, cuando los neutrófilos son co-cultivaron con PBMC, la polarización celular es de suma importancia para el aumento significativo de la capacidad de matar las micobacterias. Ya la expresión génica de los neutrófilos de pacientes con tuberculosis mostró disminución de los genes TLR4, LCN2 y Dectin1. El CCR7 mostró una correlación negativa con la progresión de la tuberculosis, por lo que la mayor parte CCR7 expresión se asocia con menor severidad. La expresión de genes también mostró diferencias en el perfil de los neutrófilos durante las diferentes etapas de la activación de Mtb. Este resultado apoya la idea de plasticidad de los neutrófilos de acuerdo con el microambiente y ayudar a entender mejor cómo los subtipos de neutrófilos pueden tener diferentes acciones en contra de Mtb. Además, se indica que el N2 están más relacionadas con la enfermedad en su etapa más severa, la prevención de la resolución óptima de la infección que se asoció con el perfil N1.

Palabras clave: neutrófilos, Mycobacterium tuberculosis, plasticidad, la tuberculosis. 


\section{LISTA DE FIGURAS}

Figura 1. Mapa ilustrando a incidência de casos de tuberculose em 2015

Figura 2. A origem e a diferenciação de células tumorais derivadas de células mielóides

Figura 3. Representação esquemática do delineamento experimental realizada durante o estudo

Figura 4: Caracterização dos neutrófilos polarizados revelaram diferenças na morfologia nuclear e na atividade metabólica

Figura 5. Análise da expressão gênica das populações de neutrófilos diferenciadas in vitro com os meios condicionantes para N1 e N2.

Figura 6: Quantificação de citocinas a partir do sobrenadante dos neutrófilos polarizados e infectados por Mtb por 24 horas.

Figura 7. A polarização in vitro dos neutrófilos não modifica a sua capacidade fagocítica e microbicida quando infectados com M. tuberculosis.

Figura 8. Os neutrófilos polarizados não modulam a capacidade de fagocitose das células mononucleares.

Figura 9. Os neutrófilos polarizados mostram diferentes atividades microbicidas quando cocultivados com PBMC.

Figura 10. A liberação de NET durante a infecção micobacteriana pode ser alterada de acordo com o subtipo de neutrófilo envolvido no processo.

Figura 11. Expressão gênica de neutrófilos de pacientes com tuberculose ativa sugere uma polarização celular.

Figura 12. Correlação entre expressão gênica e gravidade da doença em pacientes com tuberculose.

Figura 13. Expressão gênica de neutrófilos em diferentes tempos em uma infecção por Mycobacterium tuberculosis.

Figuras suplementares

Figura S1: Quantificação de citocinas e quimiocinas presentes no plasma de pacientes com tuberculose

Figura S2: Correlação entre a gravidade da doença tuberculosa em pacientes com tuberculose e a expressão gênica 


\section{LISTA DE ABREVIATURAS}

$\mu g$ : Micrograma

a.C.: Antes de cristo

AIDS: Síndrome da imunodeficiência adquirida

ALOX15: Arachidonate 15-Lipoxygenase

APTB: Paciente com tuberculose ativa

BCG: Bacilo Calmette-Guerrim

BSA: Albumina sérica bovina

CCR7: Receptor de quimiocina tipo 7

cDNA: ácido desoxirribonucleico complementar

CEP: Comitê de Ética em Pesquisa

cpm: Contagem de fotóns por minuto

CR3: Receptor para complemento tipo 3

$\mathrm{CO}_{2}$ : Dióxido de carbono

CTRL: Controle

DAPI: 4',6-diamidino-2-fenilindol

DNA: Ácido desoxirribonucleico

DOTS: Directly Observed Treatment Shortcourse

ELISA: Enzyme linked immunosorbent assay

ERO: Espécie reativa de oxigênio

FCFRP: Faculdade de Ciências Farmacêuticas de Ribeirão Preto

GAPDH: Proteína gliceraldeído-3-fosfato desidrogenase

GM-CSF: Fator estimulador de colônias monócitos granulócitos
HDNs: Neutrófilos de alta densidade

HIV: Vírus da imunodeficiência humana

HN1: Peptídeos de neutrófilos humanos tipo 1

HN2: Peptídeos de neutrófilos humanos tipo 2

HN3: Peptídeos de neutrófilos humanos tipo 3

HN4: Peptídeos de neutrófilos humanos tipo 4

IFN- $\gamma$ : Interferon gama

IL-1 $\beta$ : Interleucina 1 beta

IL-10: Interleucina 10

IL-12: Interleucina 12

IL-13: Interleucina 13

IL-17: Interleucina 17

IL-4: Interleucina 4

IL-8: Interleucina 8

IP-10: Interferon gamma-induced protein 10

LAM: lipoarabinomanana

LAS: Leica application suíte

LCN2: Lipocalin-2

LDNs: Neutrófilos de baixa densidade

LPS: Lipopolis sacarídeo

M. bovis: Mycobacterium bovis

MDR: cepas multiressistentes

mg: Microgramas

$\mathrm{mL}$ : Mililitro

mm: Milimetros

MOI: Multiplicity of infection 
mRNA: Ácido ribonucleico mensageiro

Mtb: Mycobacterium tuberculosis

M. tuberculosis: Mycobacterium tuberculosis

M1: Macrófago tipo 1

M2: Macrófago tipo 2

NADPH: Fosfato de dinucleotídeo de adenina e nicotinamida

NET: Neutrophil extracellular trap

ng: Nanogramas

nm: Nanometros

N0: Neutrófilo sem estímulo

N1: Neutrófilo tipo 1

N2: Neutrófilo tipo 2

OMS: Organização Mundial da Saúde

PBMC: Células polimorfo nucleares

PAMP: Padrão molecular associado à patógeno

PBS: Phosphate buffered saline

pg: Picogramas

PMA: Forbol-12-miristato-13-acetato

PRR: Receptor de reconhecimento padrão
qPCR: Reação em cadeia da polimerase em tempo real

RANTES: Regulated on activation, normal T cell expressed and secretd

RFU: Unidades de fluorescência relativa

RNA: Ácido ribonucleico

RPMI: Meio de cultura celular

SBF: Soro bovino fetal

TB: Tuberculose

TB MDR: cepas multirresistentes da tuberculose

T CD4+: Linfócito $\mathrm{T}$ auxiliar

TCLE: Termo de Consentimento Livre e Esclarecido

TGF- $\beta$ : Fator de transformação do crescimento tipo beta

Th1: Type $1 \mathrm{~T}$ helper cell

Th2: Type $2 \mathrm{~T}$ helper cell

TLR2: Receptor semelhante ao Toll 2

TLR4: Receptor semelhante ao Toll 2

TNF- $\alpha$ : Fator de necrose tumoral alfa

USP: Universidade de São Paulo 


\section{SUMÁRIO}

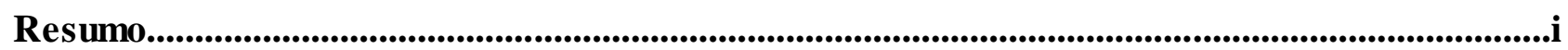

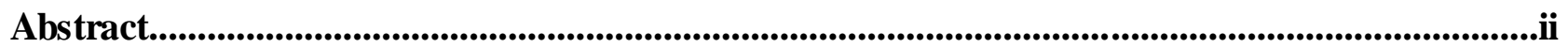

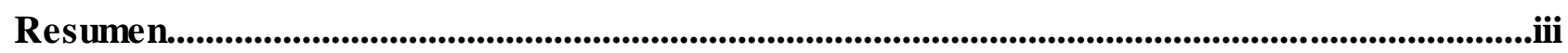

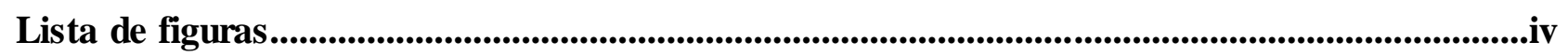

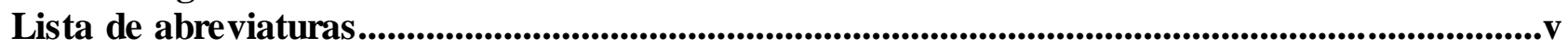

1. INTRODUÇÃ

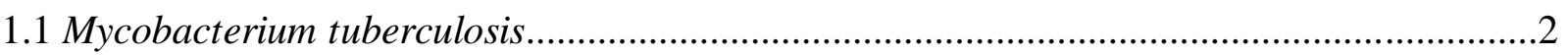

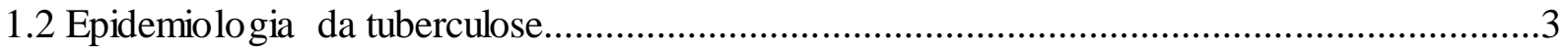

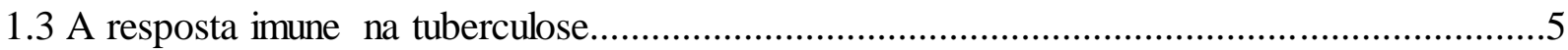

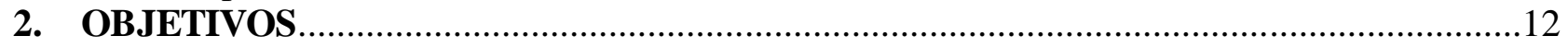

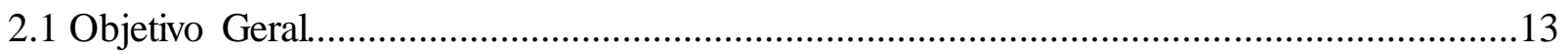

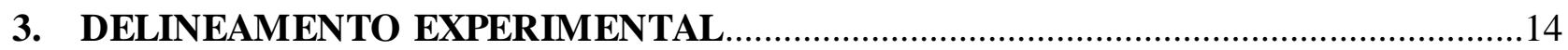

3.1 Estratégias experimentais utilizadas para alcançar os objetivos......................................15

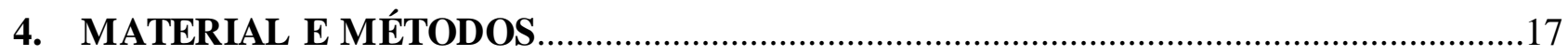

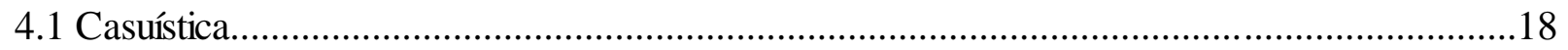

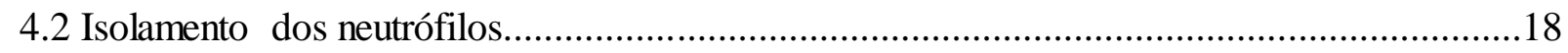

4.3 Polarização para o perfil N1 e N2 .................................................................................19

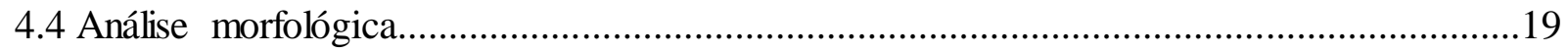

4.5 Produção de espécies reativas de oxigênio (EROs).........................................................19

4.6 Crescimento bacteriano e estimulação dos neutrófilos........................................................20

4.7 Quantificação de citocinas liberadas no sobrenadante de cultura ......................................20

4.8 Atividade fagocítica e microbicida das culturas de neutrófilos.........................................21

4.9 Atividade fagocítica e microbicida da co-cultura de neutrófilos e polimorfonucleares (PBMC)

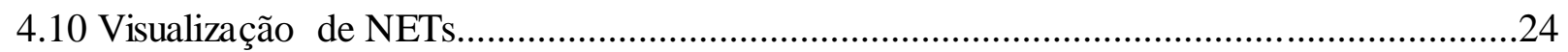

4.11 Extração de RNA e síntese de cDNA..........................................................................25

4.12 Análise de expressão gênica - PCR em tempo real.........................................................26

4.13 Correlações entre a gravidade da tuberculose e a expressão gênica de neutrófilos de

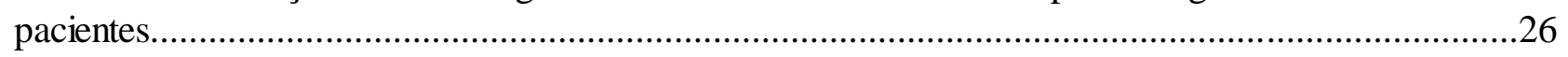

4.14 Estimulação de neutrófilos através do plasma de pacientes de tuberculose.......................27

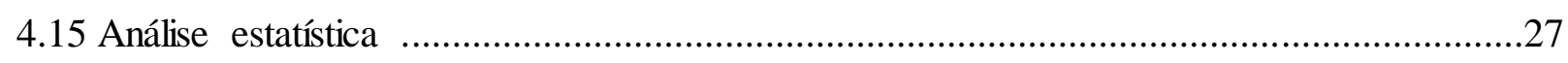

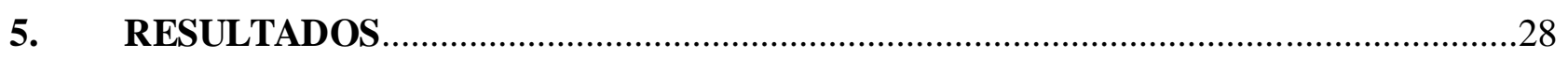

5.1 A polarização dos neutrófilos induz diferenças na morfologia nuclear e na atividade metabólica..

5.2 Análise da expressão gênica apresentada por neutrófilos polarizados in vitro para os perfis $\mathrm{N} 1$ e N2. 
5.3 Os neutrófilos polarizados e infectados por $M$. tuberculosis revelaram diferenças na resposta imune. .33

5.4 A modulação na resposta imune promovida pelos diferentes subtipos de neutrófilos reflete no controle microbiano

5.5 Modulação na liberação de armadilhas extracelulares (NET) pelos diferentes subtipos de neutrófilos. .39

5.6 Análise da expressão gênica dos neutrófilos de pacientes com tuberculose .43

5.7 Busca de correlações entre os níveis de expressão gênica e a progressão da tuberculose 44

5.8 As diferenças no perfil de expressão genética dos neutrófilos durante as distintas fases de infecção. 45

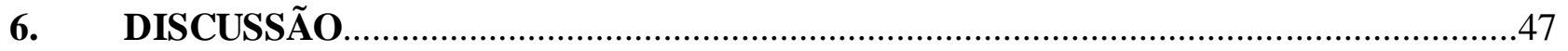

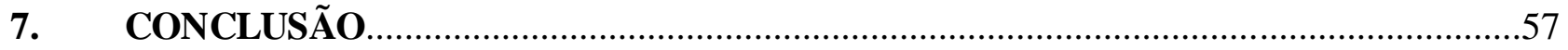

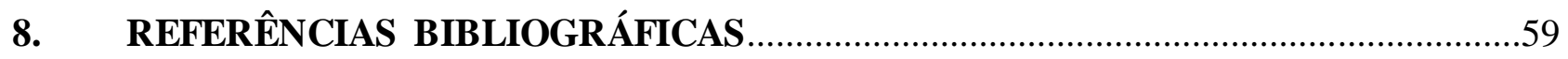

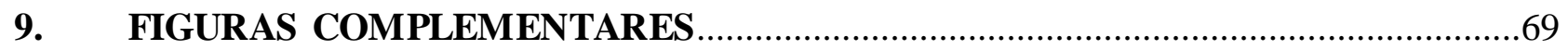

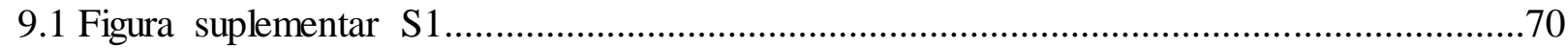

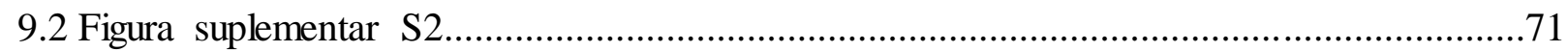

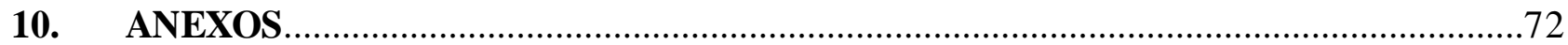

10.1 ANEXO I: Parecer do Comitê de Ética em Pesquisa........................................................73

10.2 ANEXO II: Parecer do Comitê de Ética em Pesquisa........................................................75

10.3 ANEXO III: Termo de Consentimento Livre e Esclarecido.............................................77 


\subsection{Mycobacterium tuberculosis}

O bacilo Mycobacterium tuberculosis (Mtb), isolado por Robert Koch em 1882, é considerado um bacilo Gram-positivo. Sua parede celular possui características peculiares sendo composta por $60 \%$ de lipídios, incluindo LAM (lipoarabinomanana) e ácido micólico (Collins and Kaufmann, 2001), além disso, é seletiva a uma grande quantidade de substâncias. Essa micobactéria é a responsável por causar a tuberculose, uma doença muito antiga que tem acompanhado a humanidade ao longo de sua evolução. Assim como outras doenças, ao longo da história, apesar de exibir momentos de grandes epidemias e depois de recuo nas taxas de infecção, o M. tuberculosis pode ter matado mais pessoas do que qualquer outro patógeno microbiano (Daniel, 2006).

Pode-se supor que o gênero Mycobacterium originou-se à mais de 150 milhões anos. Modernas técnicas de genética molecular e sequenciamento do genoma de várias cepas de Mtb permitiram uma estimativa mais rigorosa do tempo de origem das micobactérias. Esta estimativa é facilitada pela baixa taxa de mutação das mesmas. Desta forma, estima-se que um progenitor precoce de Mtb estava presente na África Oriental há 3 milhões de anos atrás, e que esses bacilos poderiam ter infectado os primeiros hominídeos naquele tempo (Gutierrez et al., 2005).

Esses dados revelam que desde a antiguidade o bacilo Mtb, causador da tuberculose (TB), tem estado presente na população humana. Fragmentos da coluna vertebral de múmias egípcias datadas de 2400 a.C. mostram sinais claros de TB (Zink et al., 2001). A doença exemplifica um caso de co-evolução entre patógeno e hospedeiro (Hershkovitz et al., 2008) e levando-se em consideração esta mútua adaptação, pode-se compreender o caráter pandêmico da TB e o motivo pelo qual, na maioria dos casos, se manifesta após um grande período de latência. Desta forma, não é comum desenvolver a forma ativa da doença após o contato primário com o bacilo. 


\subsection{Epidemiologia da tuberculose}

A tuberculose ainda é um sério problema de saúde pública, com profundas raízes sociais (Ministério_Da_Saúde, 2013). Esta patologia está intimamente ligada à má distribuição de renda e aos maus hábitos, que favorecem situações de maior vulnerabilidade, como o alcoolismo e tabagismo. A partir do último relatório global de TB realizado pela Organização Mundial da Saúde (OMS), estima-se que houve 10,4 milhões de novos casos de tuberculose em todo o mundo e que 1,8 milhões de pessoas morreram de TB no ano de 2015 (Who, 2016).

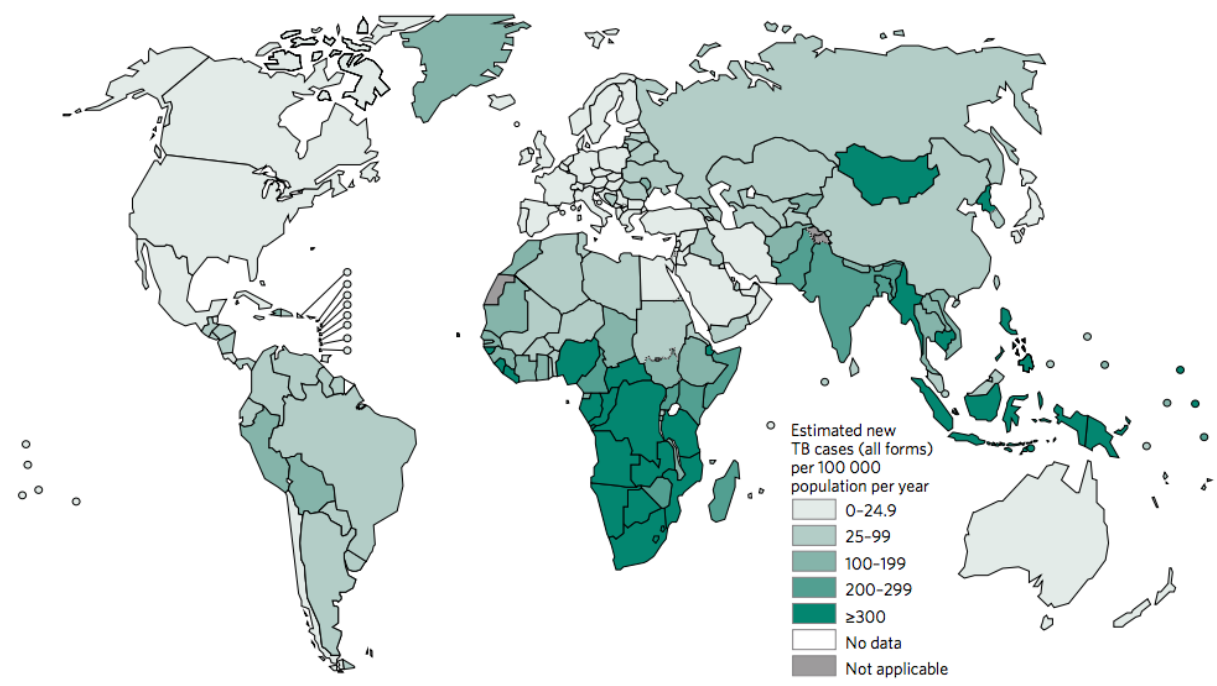

Figura 1. Mapa ilustrando a incidência de casos de tuberculose em 2015. Estimativa do número de novos casos de tuberculose (todas as formas) por 100 mil pessoas $\begin{array}{lllll}\text { Modificado de Global Tuberculosis } & \text { Control, } & 2016 .\end{array}$ http://apps.who.int/iris/bitstream/10665/250441/1/9789241565394-eng.pdf:).

O aumento global da incidência da TB alcançou seu pico em 2004 e foi seguido de uma lenta queda, compensado pelo crescimento da população. O número de casos continua aumentando anualmente, principalmente nas regiões menos desenvolvidas do globo, como África, Mediterrâneo Oriental e Sudeste Asiático. Entretanto, a história de combate à epidemia por meio da vacinação, data de 1921 quando na tentativa de conter o desenvolvimento da doença na população humana, Albert Calmette e Camille Guérin 
desenvolveram a vacina BCG (Bacilo Calmette-Guérrin). A BCG é constituída por cepas vivas atenuadas do bacilo $M$. bovis, sendo até os dias de hoje, a única vacina contra tuberculose aprovada e disponível para a população mundial.

Embora essa vacina seja utilizada em muitos países, principalmente em regiões com alto índice de TB, a sua eficiência é parcial. Desta forma a BCG é recomendada pela OMS em áreas de alta prevalência da doença, sendo capaz de prevenir a forma disseminada da TB, bem como outras manifestações da infecção em crianças, como a meningite (Roth et al., 2006; Setia et al., 2006). No entanto, nos adultos, o índice de prevenção da TB pulmonar pela BCG pode variar entre $0 \%$ e $80 \%$, de acordo com a população em questão (Svenson et al., 2010). Existem estudos em andamento para a composição de outras vacinas, baseadas ou não no BCG, mas ainda não há nenhuma que possa substituí-la, ou pelo menos ser utilizada em associação para aumentar a sua eficácia (Barker et al., 2009).

Além da disponibilidade de uma vacina contra a TB, existe também a opção terapêutica clássica composta pelas drogas Rifampicina, Pirazinamida, Etambutol e Isoniazida. $\mathrm{O}$ uso de antibioticoterapia e a vacinação marcaram a história da infecção por Mtb, sendo responsáveis pela contenção da epidemia global no século passado. Entretanto, as dificuldades de acesso a esses medicamento (em algumas localidades), além do abandono da terapia após a melhora inicial do quadro clínico, estão entre os principais fatores que fizeram com que a OMS implantasse um sistema supervisionado de terapia, o DOTS (do inglês Directly Observed Treatment Short-course). Essa orientação aumenta a probabilidade de cura dos doentes, pois garante um tratamento assistido. O DOTS foi responsável por melhoras na adesão e êxito na terapia contra a TB, no entanto, não evitou que o uso inadequado das drogas contribuísse na seleção de cepas multirresistentes (MDR) (Gandhi et al., 2010). Segundo o Ministério da Saúde do Brasil nos casos de TB com cepas resistentes o tratamento é 
prolongado, podendo ocorrer durante 24 meses, e apresentar mais efeitos colaterais. O custo dessa terapia é maior, bem como a sua chance de falhar.

Indicadores epidemiológicos revelaram que em 2015 cerca de 480.000 pessoas desenvolveram a TB multirresistente (TB-MDR) em todo o mundo, sendo que Índia, China e Federação Russa respondem por quase metade de todos os casos em nível global. Estes dados mostram que a TB-MDR continua a ser uma crise de saúde pública.

Além deste cenário já complexo, a partir da década de 1980, o surgimento da epidemia de AIDS agravou ainda mais o problema da doença no mundo. Devido à imunossupressão enfrentada pelos pacientes HIV positivos, tornam-se evidentes a susceptibilidade à infecção e à reativação da TB latente. A tuberculose é uma das principais co-infecções no paciente HIV + e que acarreta maior morbidade e mortalidade (Granich et al., 2010). Após este agravante na história da TB, quando os casos aumentaram de forma muito significativa, a OMS estabeleceu na conferência ministerial sobre Tuberculose e Desenvolvimento Sustentável, em março de 2000, metas de combate à TB (Saúde, 2006). Entretanto, o último relatório emitido pela OMS revelou que os países precisam melhorar as formar de prevenção, de detecção e de tratamento da doença com objetivo de cumprir as metas globais. Visto que a queda do coeficiente de incidência entre os anos de 2014 e 2015 foi muito pequena, sendo de apenas 1,5\%, não atingindo a meta traçada pela Estratégia pelo Fim da Tuberculose.

\subsection{A resposta imune na tuberculose}

A infecção se inicia por meio da inalação de gotículas contendo bacilos viáveis por um indivíduo doente durante o espirro, tosse ou a fala. A TB acomete principalmente o trato respiratório inferior, sendo os pulmões o primeiro local de estabelecimento dos bacilos, contudo, podem existir outras formas de TB. A doença pulmonar ativa é caracterizada pela dor no peito, tosse intensa e prolongada por mais de três semanas, com produção de muco 
com ou sem a presença de sangue (indicativo de estágio avançado). Segundo a Organização Mundial da Saúde, o paciente ainda pode apresentar episódios de febre, perda de apetite, palidez, calafrios, cansaço, suores noturnos e emagrecimento (Saúde, 2017).

A infecção pode ainda, permanecer na sua forma latente, tal fato ocorre com aproximadamente $90-95 \%$ das pessoas infectadas. Esses pacientes com TB latente permanecem assintomáticos e não transmitem o bacilo, no entanto são caracterizados como um reservatório do patógeno. A permanência das altas taxas de incidência e prevalência da TB, pode estar associada à infecção latente, visto que a qualquer momento, um fator que gere um quadro de imunossupressão pode levar à reativação da doença (Kaufmann, 2001).

Nos casos em que a infecção assume um caráter latente, o bacilo Mtb induz a formação de uma reação inflamatória típica, onde há o acúmulo de células inflamatórias e da imunidade adaptativa ao redor do microrganismo, iniciando a formação de granulomas, fenômeno coordenado principalmente por linfócitos $\mathrm{T}$ CD4+ ativados. A formação do granuloma no foco da infecção é um dos aspectos clínicos utilizados no diagnóstico da TB pulmonar (Hernandez-Pando et al., 1997; Flynn and Ernst, 2000; Collins and Kaufmann, 2001). O granuloma, posteriormente, é envolto em fibras colágenas produzidas por fibroblastos, tal sistema pode restringir a disseminação dos bacilos por um longo tempo. Neste ambiente hostil, com baixos níveis de oxigênio e de nutrientes, o Mtb diminui seu metabolismo, caracterizando a fase de latência da infecção (Dheda et al., 2005).

Os bacilos que chegam aos alvéolos são fagocitados por macrófagos e células dendríticas, o que é facilitado por interações do patógeno com diversos receptores presentes nas células do sistema imune inato. As células reconhecem os PAMP's (Pathogen-Associated Molecular Patterns) através de Receptores de Reconhecimento de Padrões (PRR). Além dos PRRs, outros receptores do sistema imune, como o CR3 (Complement Receptor 3), facilitam a entrada do bacilo opsonizado na célula hospedeira, quando este está revestido por proteínas 
do sistema complemento, sem ocorrer a ativação da maquinaria responsável pela produção de espécies reativas de oxigênio (EROs), que possuem atividade bactericida (Tailleux et al., 2003).

Após a ativação inicial das células residentes pelo Mtb, os neutrófilos são os primeiros fagócitos recrutados do sangue para o espaço brônquio alveolar, onde liberam potentes mediadores inflamatórios e atuam na resposta contra o bacilo (D'avila et al., 2008). O papel protetor dos neutrófilos durante a resposta imune contra Mtb foi evidenciado a partir de diversas observações clínicas e experimentais, mostrando que estas células podem produzir reativos do oxigênio e nitrogênio capazes de conter a infecção (Brown et al., 1987; Perskvist et al., 2002). Outro estudo mostrou que existe uma abundante produção de peptídeos liberados exclusivamente por neutrófilos no sangue de pacientes com TB, tais como HNP-1, HNP-2, PNH-3 e PNH-4. Essas proteínas apresentam atividade quimiotática para outros leucócitos, como fagócitos e linfócitos $\mathrm{T}$, contribuindo indiretamente com a atividade microbicida por ativar a resposta imune celular contra a bactéria (Zhu et al., 2011).

Os neutrófilos podem ainda apresentar um mecanismo microbicida independente da fagocitose, que é a liberação de NETs, ou Neutrophil Extracellular Traps (Drescher and Bai, 2013). Esse mecanismo foi descrito em 2004 por Brinkmann e colaboradores que mostraram que neutrófilos humanos eram capazes de liberar uma estrutura fibrosa formada de DNA associada à histonas e à moléculas como elastase, catepsnia G e mieloperoxidase (Brinkmann et al., 2004). A mieloperoxidase é uma enzima importante que auxilia na liberação da elastase dos grânulos azurófilos, possibilitando que esta migre até o núcleo da célula e realize a degradação de histonas, ligadas ao material genético, proporcionando a sua descondensação e a liberação do DNA (Papayannopoulos et al., 2010). Outro fator importante para esse processo é a presença de EROs (Fuchs et al., 2007; Bianchi et al., 2009; Nishinaka et al., 2011). Experimentos com substancias antioxidantes reforçaram essa ideia, de forma que o uso 
de "scavenger" de EROs, interferência na ação de NADPH oxidase e da mieloperozidase impedem a liberação das NETs (Kirchner et al., 2012; Mohammed et al., 2013; Vorobjeva and Pinegin, 2016). Esse mecanismo se mostra importante no controle de diversas infecções, em que o patógeno apresenta estratégias de escape do espaço intracelular, como pode ocorrer no caso da Mtb. Desta forma, essa rede aprisiona muitos tipos de microrganismos, podendo assim, levá-los a morte, expondo-os a alta concentração de substâncias microbicidas, ou até proporcionando a apresentação de antígenos para outras células do sistema imunológico (Amulic and Hayes, 2011; Braian et al., 2013). A interação entre neutrófilos e Mtb é capaz de desencadear a formação das NETs, assim, embora a micobactéria seja resistente à morte no interior desse tipo celular esse mecanismo a apreende no meio extra celular e pode levar a sua eliminação (Braian et al., 2013).

No inicio da infecção os neutrófilos auxiliam efetivamente na contenção do parasita, no entanto, ainda há a possibilidade de disseminação de bacilos viáveis. Caso a infecção não possa ser contida, em um primeiro momento, as interações entre neutrófilos e demais fagócitos podem dirigir a resposta de células $\mathrm{T}$, podendo assim, determinar o resultado clínico e imunológico da infecção (Dorhoi and Kaufmann, 2014). Assim, temos que a resposta pode ser rápida e eficaz controlando a replicação da micobacteria ou então pode ser insuficiente, levando a uma inflamação exacerbada e a progressão da doença. Portanto, na fase avançada da TB os neutrófilos podem contribuir para a patologia, mas também podem representar um mecanismo compensatório do hospedeiro, em face à replicação bacteriana descontrolada (Lowe et al., 2012).

Alguns estudos sugeriram o papel negativo dos neutrófilos na patogênese da tuberculose. Em linhagens de camundongos geneticamente suscetíveis infectados experimentalmente e em pacientes com tuberculose ativa, foi mostrado que a insuficiência respiratória e mortalidade estavam associadas a um aumento do número de neutrófilos no 
sangue (Barnes et al., 1988; Eruslanov et al., 2005; Keller et al., 2006). A abundância de neutrófilos em casos de infecção avançada está associada à liberação de mediadores que podem causar danos ao tecido se não forem rigorosamente controlados (Eum et al., 2010; Marzo et al., 2014).

Uma descoberta recente mostrou que o IFN- $\gamma$ é capaz de inibir a produção de IL-17 por células $\mathrm{T}$ CD4+, prejudicando a sobrevivência de neutrófilos, muito embora contribua para o aumento dos mesmos no sítio infeccioso. Tal fato acarreta em um aumento da inflamação do pulmão e a progressão da doença. Desta forma, a neutrofilia durante a TB pode indicar falha na resposta inflamatória ou a perda da capacidade de resposta ao IFN- $\gamma$ (Nandi and Behar, 2011; O'garra et al., 2013).

Classicamente a resposta imune eficaz contra Mtb é associada ao predomínio do padrão TH1 sobre o padrão TH2 de resposta no hospedeiro. Interessantemente, alguns autores têm descrito a participação de células que comumente seriam relacionadas a processos alérgicos e/ou na eliminação de helmintos, produtoras de citocinas $\mathrm{TH} 2$, participando da resposta imune conta o bacilo (Ashenafi et al., 2014). Assim, evidências crescentes sugerem que um equilibrio Th1 / Th2 é crucial para controlar a progressão da tuberculose ativa. A IL12 , IFN- $\gamma$ e TNF- $\alpha$ contribuem para a indução de proteção mediada por Thl em TB, ao passo que o aumento dos níveis de IL-10 promovem o desenvolvimento de uma resposta de Th2. A IL-10 antagoniza com as citocinas pró-inflamatórias, reprimindo a inflamação exacerbada e levando ao reparo tecidual (Dorhoi and Kaufmann, 2014).

Semelhante à dicotomia Th1 e Th2 de polarização das células T, os macrófagos podem ser polarizados no microambiente para montar respostas M1 e M2 (Biswas and Mantovani, 2010). Produtos microbianos como o LPS, ou o IFN- $\gamma$ da resposta imune do hospedeiro são capazes de ativar os macrófagos, induzindo a polarização clássica para o padrão M1. Nessa ativação, os macrófagos se tornam potentes efetores que matam microrganismos intracelulares 
e produzem grandes quantidades de citocinas pró-inflamatórias (Sica, A and Mantovani, A, 2012). Em contraste, a ativação alternativa de macrófagos M2 é bem diversa, mas em geral, está envolvida na resposta Th2. Tal ativação atua na imunorregulação, o encapsulamento, a contenção de parasitas, além de promover a reparação tecidual, remodelação e progressão de tumores (Sica, A. and Mantovani, A., 2012). Tal polarização foi bem descrita nessas células e recentemente novos estudos quebram paradigmas também em relação aos neutrófilos. Estes estudos revelaram que estes granulócitos apresentam plasticidade e que também podem apresentar diferentes fenótipos de acordo com o microambiente (Mantovani et al., 2011).

Fridlender et al. (Fridlender et al., 2009) forneceu evidências para a existência da polarização dos neutrófilos associados a tumores, N1 (antitumoral) e N2 (pró-tumoral) (Figura 2). Em analogia à polarização que ocorre em macrófagos M1 e M2. Em alguns casos de neoplasia os neutrófilos adquirem diferentes fenótipos, podendo auxiliar na contenção das células cancerígenas e na rejeição tumoral (N1) ou propiciar o crescimento tumoral, invasão e metástase (N2) (Piccard et al., 2012). A ideia de diferentes fenótipos de um tipo celular coexistir no decorrer do câncer não estava esclarecida e havia muitas controvérsias se a polarização N1 e N2 ocorriam concomitantemente. Estudos recentes revelam que existe subpopulações de neutrófilos na corrente sanguínea e que as mesmas possuem proporções de ocorrências diferentes de acordo com a progressão da doença (Sagiv et al., 2015). 


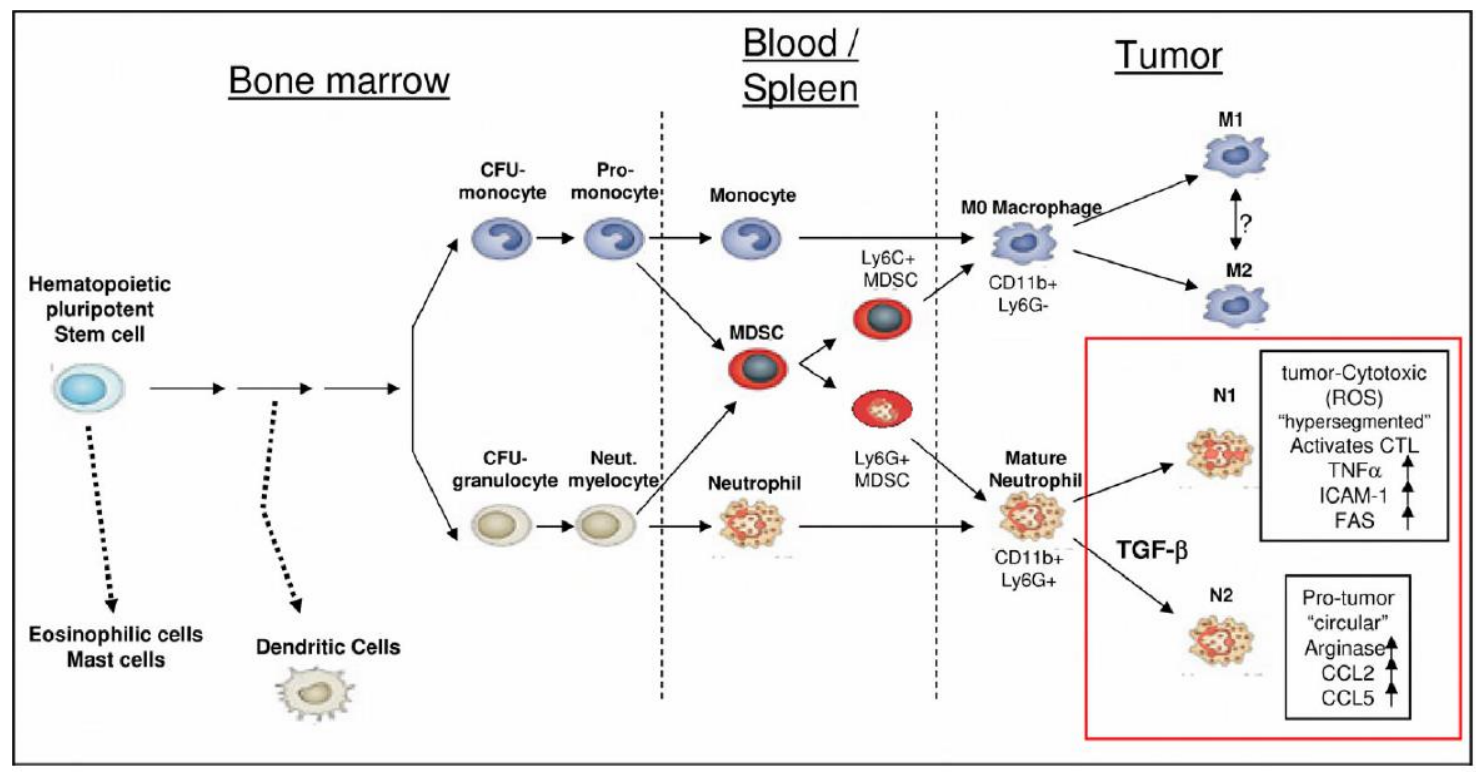

Figura 2. A origem e a diferenciação de células tumorais derivadas de células mielóides. Retirado de (Fridlender et al, 2009 (Fridlender et al., 2009)), baseado em (Murdoch et al., 2008 (Murdoch et al., 2008)) e (Gabrilovich and Nagaraj, 2009 (Gabrilovich and Nagaraj, 2009)).

Os novos achados sobre a plasticidade e a dinâmica dos neutrófilos em casos de câncer revelam uma perspectiva no estudo da infecção por Mtb e progressão para a doença ativa. A M. tuberculosis proporciona uma diferente ativação e modulação na polarização dos macrófagos (Lugo-Villarino et al., 2011), no entanto, não há registro da influência da polarização dos neutrófilos no controle da tuberculose. 
Conclusão

Esse estudo revelou que é possível promover a polarização dos neutrófilos, por meio de meios condicionados, além disso, mostramos como os perfis N1 e N2 desempenham diferentes respostas em uma infecção por Mtb. De forma que, N2 apresentou uma maior produção de citocinas anti-inflamatórias, e que apesar de poder auxiliar na morte de micobactérias previamente fagocitadas por monócitos esse tipo celular é incapaz de liberar NET. Já os neutrófilos N1 apresentaram uma elevada produção de ROS, IL-1 $\beta$, IFN- $\gamma$ e IL-8, todos esses mediadores potencializaram a atividade microbicida, além de proporcionar a maior liberação de NET.

Por meio da expressão gênica foi possível caracterizar os perfis N1 e N2 e traçar qual é mais abundante em pacientes com tuberculose, bem como fazer correlações com a gravidade da doença. O perfil N2 apresentou aumento na expressão de genes como ALOX-15 e IP-10, além da diminuição de genes importantes para o controle da TB. A caracterização gênica de N2 é muito similar ao perfil de expressão gênica amostrada pelos pacientes com tuberculose, devido ao aumento de IP-10, ALOX15, bem como a diminuição de DECTIN-1 e LCN2. Essas semelhanças nos permite inferir que N2 é mais abundante durante a infecção. Em contrapartida o perfil gênico de N1, com o aumento de Dectina1 e LCN2 está mais relacionada com a proteção contra a TB. Por fim, a correlação entre os dados clínicos e a expressão gênica dos neutrófilos revelou uma correlação negativa com a gravidade da doença, no caso de CCR7 e outra correlação positiva quando avaliado a expressão de TLR4.

Nosso trabalho mostrou que os neutrófilos podem se polarizar de acordo com o microambiente e que os perfis N1 e N2 possuem diferentes atuações na infecção por Mtb. De forma que, N1 está relacionado com o controle e resolução da infecção, enquanto que a presença de N2 sinaliza um pior prognóstico. Além disso, mostramos que os neutrófilos N1 e N2 são alvos promissores para o entendimento do desenvolvimento da tuberculose e até de outras doenças. 
ABAKAY, $O$. et al. The relationship between inflammatory marker levels and pulmonary tuberculosis severity. Inflammation, v. 38, n. 2, p.691-6, Apr 2015. ISSN 1573-2576. Available at: < https://www.ncbi.nlm.nih.gov/pubmed/25028104 >.

ABEL, B. et al. Toll-like receptor 4 expression is required to control chronic Mycobacterium tuberculo sis infection in mice. J Immunol, v. 169, n. 6, p. 3155-62, Sep 2002. ISSN 0022-1767. Available at:< https://www.ncbi.nlm.nih.gov/pubmed/12218133 >.

AMULIC, B.; HAYES, G. Neutrophil extracellular traps. Curr Biol, v. 21, n. 9, p. R297-8, May 2011. ISSN 18790445. Availableat:<http://www.ncbi.nlm.nih.gov/pubmed/21549944 $>$.

ASHENAFI, S. et al. Progression of clinical tuberculosis is associated with a Th 2 immune response signature in combination with elevated levels of SOCS3. Clin Immunol, v. 151, n. 2, p. 84-99, Apr 2014. ISSN 15217035. Availableat:< http://www.ncbi.nlm.nih.gov/pubmed/24584041 $>$.

BARKER, L. F. et al. Tuberculosis vaccine research: the impact of immunology. Curr Opin Immunol, v. 21, n. 3, p. 331-8, Jun 2009. ISSN 1879-0372. Available at:<http://www.ncbi.nlm.nih.gov/pubmed/19505813 >.

BARNES, P. F. et al. Predictors of short-term prognosis in patients with pulmonary tuberculosis. J Infect Dis, v. 158, n. 2, p. 366-71, Aug 1988. ISSN 0022-1899. Availableat:<

http://www.ncbi.nlm.nih.gov/pubmed/3403993 >.

BEAUVILLAIN, C. et al. CCR7 is involved in the migration of neutrophils to lymph nodes. Blood, v. 117, n. 4, p. 1196-204, Jan 2011. ISSN 1528-0020. Availableat:<https://www.ncbi.nlm.nih.gov/pubmed/21051556 >

BIANCHI, M. et al. Restoration of NET formation by gene therapy in CGD controls aspergillosis. Blood, $\mathrm{v}$. 114, n. 13, p. 2619-22, Sep 2009. ISSN 1528-0020. Available at:<

https://www.ncbi.nlm.nih.gov/pubmed/19541821 >.

BISWAS, S. K.; MANTOVANI, A. Macrophage plasticity and interaction with lymphocyte subsets: cancer as a paradigm. Nat Immunol, v. 11, n. 10, p. 889-96, Oct 2010. ISSN 1529-2916. Available at:< http://www.ncbi.nlm.nih.gov/pubmed/20856220 >.

BORREGAARD, N.; SØRENSEN, O. E.; THEILGAARD-MÖNCH, K. Neutrophil granules: a library of innate immunity proteins. Trends Immunol, v. 28, n. 8, p. 340-5, Aug 2007. ISSN 1471-4906. Availableat:< https://www.ncbi.nlm.nih.gov/pubmed/17627888 >.

BRAIAN, C.; HOGEA, V.; STENDAHL, O. Mycobacterium tuberculosis-induced neutrophil extracellular traps activate human macrophages. J Innate Immun, v. 5, n. 6, p. 591-602, 2013. ISSN 1662-8128. Available at:< http://www.ncbi.nlm.nih.gov/pubmed/23635526 >. 
BRANZK, N. et al. Neutrophils sense microbe size and selectively release neutrophil extracellular traps in response to large pathogens. Nat Immunol, v. 15, n. 11, p. 1017-25, Nov 2014. ISSN 1529-2916. Available at: <https://www.ncbi.nlm.nih.gov/pubmed/25217981 >.

BRINKMANN, V. et al. Neutrophil extracellular traps kill bacteria. Science, v. 303, n. 5663, p. 1532-5, Mar 2004. ISSN 1095-9203. Available at:<https://www.ncbi.nlm.nih.gov/pubmed/15001782 >.

BROWN, A. E.; HOLZER, T. J.; ANDERSEN, B. R. Capacity of human neutrophils to kill Mycobacterium tuberculosis. J Infect Dis, v. 156, n. 6, p. 985-9, Dec 1987. ISSN 0022-1899. Available at:< http://www.ncbi.nlm.nih.gov/pubmed/2824628 >.

COLLINS, H. L.; KAUFMANN, S. H. The many faces of host responses to tuberculosis. Immunology, v. 103, n. 1, p. 1-9, May 2001. ISSN 0019-2805. Availableat:<http://www.ncbi.nlm.nih.gov/pubmed/11380686 >.

D'AVILA, H. et al. Neutrophils recruited to the site of Mycobacterium bovis BCG infection und ergo apoptosis and modulate lipid body biogenesis and prostaglandin E production by macrophages. Cell Microbiol, v. 10, n. 12, p. 2589-604, Dec 2008. ISSN 1462-5822 (Electronic). Available at:< http://www.ncbi.nIm.nih.gov/entrez/query.fcgi?cmd=Retrieve\&db=PubMed\&dopt=Citation\&list_uids=187 $\underline{71558}>$.

DANIEL, T. M. The history of tuberculosis. Respir Med, v. 100, n. 11, p. 1862-70, Nov 2006. ISSN 0954-6111. Available at:<http://www.ncbi.nlm.nih.gov/pubmed/16949809 $>$.

DHEDA, K. et al. In vivo and in vitro studies of a novel cytokine, interleukin 4 delta 2, in pulmonary tuberculosis. American Journal of Respiratory and Critical Care Medicine, v. 172, n. 4, p. 501-508, AUG 15 2005 2005. ISSN 1073-449X.

DORHOI, A.; KAUFMANN, S. H. Perspectives on host adaptation in response to Mycobacterium tuberculosis: modulation of inflammation. Semin Immunol, v. 26, n. 6, p. 533-42, Dec 2014. ISSN 1096-3618. Available at: < http://www.ncbi.nlm.nih.gov/pubmed/25453228 >.

DORHOI, A.; REECE, S. T.; KAUFMANN, S. H. For better or for worse: the immune response against Mycobacterium tuberculosis balances pathology and protection. Immunol Rev, v. 240, n. 1, p. 235-51, Mar 2011. ISSN 1600-065X. Available at:<https://www.ncbi.nlm.nih.gov/pubmed/21349097 >.

DRESCHER, B.; BAI, F. Neutrophil in viral infections, friend or foe? Virus Res, v. 171, n. 1, p. 1-7, Jan 2013. ISSN 1872-7492. Available at:<http://www.ncbi.nlm.nih.gov/pubmed/23178588 >.

ERUSLANOV, E. B. et al. Neutrophil responses to Mycobacterium tuberculosis infection in genetically susceptible and resistant mice. Infect Immun, v. 73, n. 3, p. 1744-53, Mar 2005. ISSN 0019-9567. Available at: $\langle$ http://www.ncbi.nlm.nih.gov/pubmed/15731075 $>$. 
EUM, S. Y. et al. Neutrophils are the predominant infected phagocytic cells in the airways of patients with active pulmonary TB. Chest, v. 137, n. 1, p. 122-8, Jan 2010. ISSN 1931-3543. Available at:< http://www.ncbi.nlm.nih.gov/pubmed/19749004 >.

FERWERDA, G. et al. Dectin-1 synergizes with TLR2 and TLR4 for cytokine production in human primary monocytes and macrophages. Cell Microbiol, v. 10, n. 10, p. 2058-66, Oct 2008. ISSN 1462-5822. Available at: < https://www.ncbi.nlm.nih.gov/pubmed/18549457 >.

FLYNN, J. L. et al. An essential role for interferon gamma in resistance to Mycobacterium tuberculosis infection. J Exp Med, v. 178, n. 6, p. 2249-54, Dec 1993. ISSN 0022-1007. Availableat:< https://www.ncbi.nlm.nih.gov/pubmed/7504064 >.

FLYNN, J. L.; ERNST, J. D. Immune responses in tuberculosis. Curr Opin Immunol, v. 12, n. 4, p. 432-6, Aug 2000. ISSN 0952-7915. Available at:<http://www.ncbi.nlm.nih.gov/pubmed/10899019 $>$.

FRIDLENDER, Z. G. et al. Polarization of tumor-associated neutrophil phenotype by TGF-beta: "N1"versus "N2" TAN. Cancer Cell, v. 16, n. 3, p. 183-94, Sep 2009. ISSN 1878-3686. Available at:< http://www.ncbi.nlm.nih.gov/pubmed/19732719 >.

FRIEDLAND, J.S. et al. Inhibition of ex vivo proinflammatory cytokine secretion in fatal Mycobacterium tuberculosis infection. Clin Exp Immunol, v. 100, n. 2, p. 233-8, May 1995. ISSN 0009-9104. Available at:< https://www.ncbi.nlm.nih.gov/pubmed/7743661 >.

FUCHS, T. A. et al. Novel cell death program leads to neutrophil extracellular traps. J Cell Biol, v. 176, n. 2, p. 231-41, Jan 2007. ISSN 0021-9525. Availableat:<https://www.ncbi.nlm.nih.gov/pubmed/17210947 >.

GABRILOVICH, D. I.; NAGARAJ, S. Myeloid-derived suppressor cells as regulators of the immune system. Nat Rev Immunol, v. 9, n. 3, p. 162-74, Mar 2009. ISSN 1474-1741. Available at: < http://www.ncbi.nlm.nih.gov/pubmed/19197294 >.

GANDHI, N. R. et al. Multidrug-resistant and extensively drug-resistant tuberculosis: a threat to global control of tuberculosis. Lancet, v. 375, n. 9728, p. 1830-43, May 2010. ISSN 1474-547X. Available at:< http://www.ncbi.nlm.nih.gov/pubmed/20488523 >.

GARLANDA, C. et al. Damping excessive inflammation and tissue damage in Mycobacterium tuberculosis infection by Toll IL-1 receptor 8/single Ig IL-1-related receptor, a negative regulator of IL-1/TLR signaling. J Immunol, v. 179, n. 5, p. 3119-25, Sep 2007. ISSN 0022-1767. Available at:< https://www.ncbi.nlm.nih.gov/pubmed/17709526 >.

GODALY, G.; YOUNG, D. B. Mycobacterium bovis bacille Calmette Guerin infection of human neutrophils induces CXCL8 secretion by MyD88-dependent TLR2 and TLR4 activation. Cell Microbiol, v. 7, n. 4, p. 591601, Apr 2005. ISSN 1462-5814. Available at:<https://www.ncbi.nlm.nih.gov/pubmed/15760459 >. 
GORDON, S.; MARTINEZ, F. O. Alternative activation of macrophages: mechanism and functions. Immunity, v. 32, n. 5, p. 593-604, May 2010. ISSN 1097-4180. Availableat:<

http://www.ncbi.nlm.nih.gov/pubmed/20510870 >.

GRANICH, R. et al. Prevention of tuberculosis in people living with HIV. Clin Infect Dis, v. 50 Suppl 3, p. S215-22, May 2010. ISSN 1537-6591. Availableat:<https://www.ncbi.nlm.nih.gov/pubmed/20397951 >.

GUGLANI, L. et al. Lipocalin 2 regulates inflammation during pulmonary mycobacterial infections. PLoS One, v. 7, n. 11, p. e50052, 2012. ISSN 1932-6203. Available at:< https://www.ncbi.nlm.nih.gov/pubmed/23185529 >.

GUTIERREZ, M. C. et al. Ancient origin and gene mosaicism of the progenitor of Mycobacterium tuberculosis. PLoS Pathog, v. 1, n. 1, p. e5, Sep 2005. ISSN 1553-7366. Available at:< http://www.ncbi.nlm.nih.gov/pubmed/16201017 >.

HERNANDEZ-PANDO, R. et al. Analysis of the local kinetics and localization of interleukin-1 alpha, tumour necrosis factor-al pha and transforming growth factor-beta, during the course of experimental pulmonary tuberculosis. Immunology, v. 90, n. 4, p. 607-17, Apr 1997. ISSN 0019-2805. Available at:< http://www.ncbi.nlm.nih.gov/pubmed/9176116 >.

HERSHKOVITZ, I. et al. Detection and molecular characterization of 9,000-year-old Mycobacterium tuberculosis from a Neolithic settlement in the Eastern Mediterranean. PLoS One, v. 3, n. 10, p. e3426, 2008. ISSN 1932-6203. Available at:< http://www.ncbi.nlm.nih.gov/pubmed/18923677 >.

HOWARD, A. D.; ZWILLING, B. S. Reactivation of tuberculosis is associated with a shift from type 1 to type 2 cytokines. Clin Exp Immunol, v. 115, n. 3, p. 428-34, Mar 1999. ISSN 0009-9104. Available at:< https://www.ncbi.nlm.nih.gov/pubmed/10193414 >.

INFANTE-DUARTE, C.; KAMRADT, T. Th1/Th2 balance in infection. Springer Semin Immunopathol, v. 21, n. 3, p. 317-38, 1999. ISSN 0344-4325. Availableat:<https://www.ncbi.nlm.nih.gov/pubmed/10666776 >.

JANG, E. et al. Secreted protein lipocalin-2 promotes microglial M1 polarization. FASEB J, v. 27, n. 3, p. 1176-90, Mar 2013. ISSN 1530-6860. Available at:<https://www.ncbi.nlm.nih.gov/pubmed/23207546 >.

KAHNERT, A. et al. Mycobacterium tuberculosis triggers formation of lymphoid structure in muri ne lungs. J Infect Dis, v. 195, n. 1, p. 46-54, Jan 2007. ISSN 0022-1899. Available at:< https://www.ncbi.nlm.nih.gov/pubmed/17152008 >.

KAUFMANN, S. H. How can immunology contribute to the co ntrol of tuberculosis? Nat Rev Immunol, v. 1, n. 1, p. 20-30, Oct 2001. ISSN 1474-1733. Available at: < http://www.ncbi.nlm.nih.gov/pubmed/11905811 $>$. 
KELLER, C. et al. Genetically determined susceptibility to tuberculosis in mice causally involves accelerated and enhanced recruitment of granulocytes. Infect Immun, v. 74, n. 7, p. 4295-309, Jul 2006. ISSN 00199567. Availableat:<http://www.ncbi.nlm.nih.gov/pubmed/16790804 $>$.

KESHARI, R. S. et al. Reactive oxygen species-induced activation of ERK and p38 MAPK mediates PMAinduced NETs release from human neutrophils. J Cell Biochem, v. 114, n. 3, p. 532-40, Mar 2013. ISSN 10974644. Available at:<https://www.ncbi.nlm.nih.gov/pubmed/22961925 >.

KILLICK, K. E. etal. Receptor-mediated recognition of mycobacterial pathogens. Cell Microbiol, v. 15, n. 9, p. 1484-95, Sep 2013. ISSN 1462-5822. Availableat:<https://www.ncbi.nlm.nih.gov/pubmed/23795683 >.

KIRCHNER, T. et al. The impact of various reactive oxygen species on the formation of neutrophil extracellular traps. Mediators Inflamm, v. 2012, p. 849136, 2012. ISSN 1466-1861. Available at:< https://www.ncbi.nlm.nih.gov/pubmed/22481865 >.

LABONTE, A. C.; TOSELLO-TRAMPONT, A. C.; HAHN, Y. S. The role of macrophage polarization in infectious and inflammatory diseases. Mol Cells, v. 37, n. 4, p. 275-85, Apr 2014. ISSN 0219-1032. Available at:< https://www.ncbi.nlm.nih.gov/pubmed/24625576 >.

LOWE, D. M. et al. Neutrophils in tuberculosis: friend or foe? Trends Immunol, v. 33, n. 1, p. 14-25, Jan 2012. ISSN 1471-4981. Available at:< http://www.ncbi.nlm.nih.gov/pubmed/22094048 >.

LUGO-VILLARINO, G. et al. Macrophage polarization: convergence point targeted by mycobacterium tuberculosis and HIV. Front Immunol, v. 2, p. 43, 2011. ISSN 1664-3224. Available at:< http://www.ncbi.nlm.nih.gov/pubmed/22566833 >.

MANTOVANI, A. et al. Neutrophils in the activation and regulation of innate and adaptive immunity. Nat Rev Immunol, v. 11, n. 8, p. 519-31, Aug 2011. ISSN 1474-1741. Available at:< http://www.ncbi.nlm.nih.gov/pubmed/21785456 >.

The chemokine system in diverse forms of macrophage activation and polarization. Trends Immunol, v. 25, n. 12, p. 677-86, Dec 2004. ISSN 1471-4906. Available at:< https://www.ncbi.nlm.nih.gov/pubmed/15530839 >.

MARZO, E. et al. Damaging role of neutrophilic infiltration in a mouse model of progressivetuberculosis. Tuberculosis (Edinb), v. 94, n. 1, p. 55-64, Jan 2014. ISSN 1873-281X. Available at:< http://www.ncbi.nlm.nih.gov/pubmed/24291066 >.

MEANS, T. K. et al. Human toll-like receptors mediate cellular activation by Mycobacterium tuberculosis. J Immunol, v. 163, n. 7, p. 3920-7, Oct 1999. ISSN 0022-1767. Available at: < http://www.ncbi.nlm.nih.gov/pubmed/10490993 >. 
MINISTÉRIO_DA_SAÚDE. Programa Nacional de Controle da Tubercul ose.

http://portalsaude.saude.gov.br/portalsaude/. 2013. Accessed on:03/01/2013.

MOHAMMED, B. M. et al.Vitamin C: a novel regulator of neutrophil extracellular trap formation.

Nutrients, v. 5, n. 8, p. 3131-51, Aug 2013. ISSN 2072-6643. Available at:<

https://www.ncbi.nlm.nih.gov/pubmed/23939536 >.

MONIN, L.; KHADER, S. A. Chemokines in tuberculosis: the good, the bad and the ugly. Semin Immunol, v. 26, n. 6, p. 552-8, Dec 2014. ISSN 1096-3618. Available at:<

https://www.ncbi.nlm.nih.gov/pubmed/25444549 $>$.

MOROSANOVA, M. A. et al. Mechanisms of Inflammatory Injury of Renal Tubular Cells in a Cellular Model of Pyelonephritis. Biochemistry (Mosc), v. 81, n. 11, p. 1240-1250, Nov 2016. ISSN 1608-3040. Availableat: <https://www.ncbi.nlm.nih.gov/pubmed/27914450 >.

MURDOCH, C. et al. The role of myeloid cells in the promotion of tumour angiogenesis. Nat Rev Cancer, $v$. 8, n. 8, p. 618-31, Aug 2008. ISSN 1474-1768. Available at:< http://www.ncbi.nlm.nih.gov/pubmed/18633355 >.

NANDI, B.; BEHAR, S. M. Regulation of neutrophils by interferon- $\gamma$ limits lung inflammation during tuberculosis infection. J Exp Med, v. 208, n. 11, p. 2251-62, Oct 2011. ISSN 1540-9538. Available at:< http://www.ncbi.nlm.nih.gov/pubmed/21967766 >.

NISHINAKA, Y. et al. Singlet oxygen is essential for neutrophil extracellular trap formation. Biochem Biophys Res Commun, v. 413, n. 1, p. 75-9, Sep 2011. ISSN 1090-2104. Available at:< https://www.ncbi.nlm.nih.gov/pubmed/21871447 >.

NORTH, R. J. Mice incapable of making IL-4 or IL-10 display normal resistance to infection with Mycobacterium tuberculosis. Clin Exp Immunol, v. 113, n. 1, p. 55-8, Jul 1998. ISSN 0009-9104. Available at: <https://www.ncbi.nlm.nih.gov/pubmed/9697983 >.

O'GARRA, A. et al. The immune response in tuberculosis. Annu Rev Immunol, v. 31, p. 475-527, 2013. ISSN 1545-3278. Available at:<http://www.ncbi.nlm.nih.gov/pubmed/23516984 $>$.

PAN,Z.Z. et al. Inducible lung-specific expression of RANTES: preferential recruitment of neutrophils. Am J Physiol Lung Cell Mol Physiol, v. 279, n. 4, p. L658-66, Oct 2000. ISSN 1040-0605. Available at:< https://www.ncbi.nlm.nih.gov/pubmed/11000125 >.

PAPAYANNOPOULOS, $\mathrm{V}$. et al. Neutrophil elastase and myeloperoxidase regulate the formation of neutrophil extracellular traps. J Cell Biol, v. 191, n. 3, p. 677-91, Nov 2010. ISSN 1540-8140. Available at:< https://www.ncbi.nlm.nih.gov/pubmed/20974816 >. 
PELLO, O. M. et al. Role of c-MYC in alternative activation of human macrophages and tumor-associated macrophage biology. Blood, v. 119, n. 2, p. 411-21, Jan 2012. ISSN 1528-0020. Available at:< https://www.ncbi.nlm.nih.gov/pubmed/22067385 >.

PERSKVIST, N. et al. Mycobacterium tuberculosis promotes apoptosis in human neutrophils by activating caspase-3 and altering expression of $\mathrm{Bax} / \mathrm{Bcl}$-xL via an oxygen-dependent pathway. J Immunol, v. 168, n. 12, p. 6358-65, Jun 2002. ISSN 0022-1767. Availableat:<http://www.ncbi.nlm.nih.gov/pubmed/12055253 $>$.

PICCARD, H.; MUSCHEL, R. J.; OPDENAKKER, G. On the dual roles and polarized phenotypes of neutrophils in tumor development and progression. Crit Rev Oncol Hematol, v. 82, n. 3, p. 296-309, Jun 2012. ISSN 1879-0461. Available at:<http://www.ncbi.nlm.nih.gov/pubmed/21798756 $>$.

POKKALI, S.; DAS, S. D. Augmented chemokine levels and chemokine receptor expression on immune cells during pulmonary tuberculosis. Hum Immunol, v. 70, n. 2, p. 110-5, Feb 2009. ISSN 1879-1166. Available at: < https://www.ncbi.nlm.nih.gov/pubmed/19100801 >.

RAMOS-KICHIK, V. et al. Neutrophil extracellular traps are induced by Mycobacterium tuberculosis. Tuberculosis (Edinb), v. 89, n. 1, p. 29-37, Jan 2009. ISSN 1873-281X. Availableat:< http://www.ncbi.nlm.nih.gov/pubmed/19056316 >.

ROTH, A. E. et al. Beneficial non-targeted effects of BCG--ethical implications for the coming introduction of new TB vaccines. Tuberculosis (Edinb), v. 86, n. 6, p. 397-403, Nov 2006. ISSN 1472-9792 (Print)

1472-9792 (Linking). Available at:< http://www.ncbi.nlm.nih.gov/pubmed/16901755 $>$.

RÖSZER, T. Understanding the Mysterious M2 Macrophage through Activation Markers and Effector Mechanisms. Mediators Inflamm, v. 2015, p. 816460, 2015. ISSN 1466-1861. Available at:< https://www.ncbi.nlm.nih.gov/pubmed/26089604 >.

SAGIV, J.Y. et al. Phenotypic diversity and plasticity in circulating neutrophil subpopulations in cancer. Cell Rep, v. 10, n. 4, p. 562-73, Feb 2015. ISSN 2211-1247. Available at:< http://www.ncbi.nlm.nih.gov/pubmed/25620698 >.

SAIGA, H.; SHIMADA, Y.; TAKEDA, K. Innate immune effectors in mycobacterial infection. Clin Dev Immunol, v. 2011, p. 347594, 2011. ISSN 1740-2530. Available at:< https://www.ncbi.nlm.nih.gov/pubmed/21274449 $>$.

SAÚDE, M. D. Plano Estratégico para o Controle da Tuberculose, Brasil 2007-2015., http://www.paho.org/bra/index.php?option=com_docman\&task=doc view\&gid=927\&ltemid=965, 2006. Accessed on: 27/03/2017. 
. Tuberculose. http://portalsaude.saude.gov.br/index.php/o-

ministerio/principal/secretarias/svs/tuberculose, 2017. Accessed on: 27/03/2017.

SEILER, P. et al. Rapid neutrophil response controls fast-replicating intracellular bacteria but not slowreplicating Mycobacterium tuberculosis. J Infect Dis, v. 181, n. 2, p. 671-80, Feb 2000. ISSN 0022-1899. Available at:<https://www.ncbi.nlm.nih.gov/pubmed/10669354 >.

SETIA, M. S. et al. The role of BCG in prevention of leprosy: a meta-analysis. Lancet Infect Dis, v. 6, n. 3, p. 162-70, Mar 2006. ISSN 1473-3099. Available at:< http://www.ncbi.nlm.nih.gov/pubmed/16500597 >.

SICA, A.; MANTOVANI, A. Macrophage plasticity and polarization: in vivo veritas. J Clin Invest, v. 122, n. 3, p. 787-95, Mar 2012. ISSN 1558-8238. Available at:<http://www.ncbi.nlm.nih.gov/pubmed/22378047 >.

Macrophage plasticity and polarization: in vivo veritas. Journal of Clinical Investigation, v. 122, n. 3, p. 787-795, MAR 2012 2012. ISSN 0021-9738.

SIONOV, R. V.; FRIDLENDER, Z. G.; GRANOT, Z. The Multifaceted Roles Neutrophils Play in the Tumor Microenvironment. Cancer Microenviron, v. 8, n. 3, p. 125-58, Dec 2015. ISSN 1875-2292. Available at:< https://www.ncbi.nlm.nih.gov/pubmed/24895166 >.

SMART, S. J.;CASALE, T. B. TNF-alpha-induced transendothelial neutrophil migration is IL-8dependent. Am J Physiol, v. 266, n. 3 Pt 1, p. L238-45, Mar 1994. ISSN 0002-9513. Available at:< https://www.ncbi.nlm.nih.gov/pubmed/8166294 >.

SURCEL, H. M. et al. Th1/Th2 profiles in tuberculosis, based on the proliferation and cytokine response of blood lymphocytes to mycobacterial antigens. Immunology, v. 81, n. 2, p. 171-6, Feb 1994. ISSN 0019-2805. Available at:<https://www.ncbi.nlm.nih.gov/pubmed/8157267 $>$.

SVENSON, S. et al. Towards new tuberculosis vaccines. Hum Vaccin, v. 6, n. 4, p. 309-17, Apr 2010. ISSN 1554-8619. Available at:<http://www.ncbi.nlm.nih.gov/pubmed/20372087 >.

TAILLEUX, L. et al. How is the phagocyte lectin keyboard played? Master class lesson by Mycobacterium tuberculosis. Trends Microbiol, v. 11, n. 6, p. 259-63, Jun 2003. ISSN 0966-842X. Available at:< http://www.ncbi.nlm.nih.gov/pubmed/12823942 >.

VOROBJEVA, N. V.; PINEGIN, B. V. Effects of the antioxidants Trolox, Tiron and Tempol on neutrophil extracellular trap formation. Immunobiology, v. 221, n. 2, p. 208-19, Feb 2016. ISSN 1878-3279. Available at: <https://www.ncbi.nlm.nih.gov/pubmed/26371849 $>$.

WHO, W. H. O. Global tuberculosis report. http://apps.who.int/iris/bitstream/10665/250441/1/9789241565394-eng.pdf, 2016. 
YAMADA, $\mathrm{H}$. et al. Protective role of interleukin-1 in mycobacterial infection in IL-1 al pha/beta doubleknockout mice. Lab Invest, v. 80, n. 5, p. 759-67, May 2000. ISSN 0023-6837. Available at:< https://www.ncbi.nlm.nih.gov/pubmed/10830786 >.

YAMASHITA, M. et al. Macrophages participate in lymphangiogenesis in idiopathic diffuse alveolar damage through CCL19-CCR7 signal. Hum Pathol, v. 40, n. 11, p. 1553-63, Nov 2009. ISSN 1532-8392. Availableat:< https://www.ncbi.nlm.nih.gov/pubmed/19540558 >.

ZAGER, R. A. 'Biologicmemory' in response to acute kidney injury: cytoresistance, toll-like receptor hyperresponsiveness and the onset of progressive renal disease. Nephrol Dial Transplant, v. 28, n. 8, p. 1985-93, Aug 2013. ISSN 1460-2385. Available at:<https://www.ncbi.nlm.nih.gov/pubmed/23761460 >.

ZENARO, E.; DONINI, M.; DUSI, S. Induction of Th1/Th17 immune response by Mycobacterium tuberculosis: role of dectin-1, Mannose Receptor, and DC-SIGN. J Leukoc Biol, v. 86, n. 6, p. 1393-401, Dec 2009. ISSN 1938-3673. Available at:<https://www.ncbi.nlm.nih.gov/pubmed/19773555 >.

ZHANG, J. et al. The role of lipocalin 2 in the regulation of inflammation in adipocytes and macrophages. Mol Endocrinol, v. 22, n. 6, p. 1416-26, Jun 2008. ISSN 0888-8809. Available at:< https://www.ncbi.nlm.nih.gov/pubmed/18292240 >.

ZHANG, Y. et al. Enhanced interleukin-8 release and gene expression in macrophages after exposure to Mycobacterium tubercul osis and its components. J Clin Invest, v. 95, n. 2, p. 586-92, Feb 1995. ISSN 00219738. Availableat:<https://www.ncbi.nlm.nih.gov/pubmed/7860742 >.

ZHU, L. M. et al. Multidrug-resistant tuberculosis is associated with low plasma concentrations of human neutrophil peptides 1-3. Int J Tuberc Lung Dis, v. 15, n. 3, p. 369-74, Mar 2011. ISSN 1815-7920 (Electronic) 1027-3719 (Linking). Available at:<http://www.ncbi.nlm.nih.gov/pubmed/21333105 >.

ZINK, A. et al. Molecular analysis of skeletal tuberculosis in an ancient Egyptian population. J Med Microbiol, v. 50, n. 4, p. 355-66, Apr 2001. ISSN 0022-2615. Available at: < http://www.ncbi.nlm.nih.gov/pubmed/11289521 >. 
